\title{
Anthropometric Predictors for Multiple Risk Factor Aggregation in Adults from Maracaibo City
}

\author{
Bermúdez $\mathrm{VJ}^{*}$, Rojas $\mathrm{J}^{1,2}$, Salazar $\mathrm{J}^{1}$, Añez $\mathrm{R}^{1}$, Martínez $\mathrm{MS}^{1}$, Chávez-Castillo $\mathrm{M}^{1}$, Rivas-Ríos $\mathrm{JR}^{1}$ and \\ Cabrera $\mathrm{M}^{1}$
}

${ }^{1}$ Endocrine and Metabolic Diseases Research Center, University of Zulia, Maracaibo, Venezuela

${ }^{2}$ Endocrinology Service, University Hospital of Maracaibo, Maracaibo-Zulia, Venezuela

${ }^{*}$ Corresponding author: Bermúdez VJ, MD, MSc, MPH, PhD, Endocrine and Metabolic Diseases Research Center, The University of Zulia, $20^{\text {th }}$ Avenue, Maracaibo, Venezuela 4004, Tel: 58-261-7597279, E-mail: valmore@gmail.com

\section{Citation: Bermúdez VJ, Rojas J, Salazar J, Añez R, Martínez MS, et al. (2016) Anthropometric Predictors for Multiple Risk Factor Aggregation in Adults from Maracaibo City. J Obes Overweig 2(1): 101. doi: $10.15744 / 2455-7633.2 .101$}

Received Date: July 25, 2015 Accepted Date: February 23, 2016 Published Date: February 25, 2016

\begin{abstract}
Context and Objective: There are several anthropometric measures that are useful for diagnosis obesity and also are related to the development of different cardiovascular risk factors. The purpose of this study was to determine the predictive ability of various anthropometric parameters for the multiple risk factors aggregation (MRFA) in the adult population of the city of Maracaibo-Venezuela.

Participants and Methods: This was a cross-sectional study undertaken with 1902 adult individuals of both genders. Waist circumference (WC), body mass index (BMI) and waist-height index ratio (WHtR) were determined. MRFA was defined as the presence $\geq 2$ components of metabolic syndrome (MS) except for high waist circumference. The Receiver Operating Characteristic (ROC) curve was plotted to determine the area under the curve (AUC) for each anthropometric parameter.

Results: There were $52.2 \%$ women in this study. All studied anthropometric variables were associated with MRFA $(p<0.0001)$. According to ROC curves, the best AUC for a MRFA parameter was for WHtR [Men: 0.725 (0693-0757) and Women: 0.760 (07290791)]. However when analyzing Odds Ratios, WC is the only one that exhibits association after adjustment [OR 2.6 (1.44-2.95); $p<0.01]$.

Conclusion: Waist circumference provides greater predictive ability of MRFA compared to other parameters.

Keywords: Cardiovascular risk factor; Waist circumference; Body mass index; Waist-height index ratio; Obesity; Prediction; ROC Curves

Abbreviations: AUC: Area Under the Curve; BMI: Body Mass Index; HBP: High Blood Pressure; HDL-C: High Density LipoproteinCholesterol; MRFA: Multiple Risk Factor Aggregation; MS: Metabolic Syndrome; OR: Odds Ratio; ROC: Receiver Operating Characteristic; SD: Standard Deviation; T2DM: Type 2 Diabetes Mellitus; TAG: Triacylglycerides; WC: Waist Circumference; WHO: World Health Organization; WHtR: Waist-to-Height Ratio
\end{abstract}

\section{Introduction}

Anthropometric parameters such as weight, length, skinfolds, perimeters and body diameters, are widely used in the medical field for clinical nutrition assessment, with the aim of assessing the growth, development, and determination of the individual body composition for diagnosis and prognosis for diverse pathological conditions such as low birth weight, malnutrition, and especially obesity [1].

In this sense, there are several anthropometric measures such as waist circumference (WC), body mass index (BMI), waist-hip ratio, waist-to-height ratio (WHtR), among others; which also serve as diagnostic methods for obesity [2,3]. They have also been linked to the development or progression of various cardiovascular risk factors such as dyslipidemia, high blood pressure (HBP), diabetes mellitus type 2 (T2DM) and metabolic syndrome (MS) [4,5].

Within these anthropometric measurements, BMI is the most widely used in clinical practice for the detection of obesity in the adult population, given its easy implementation, safety and minimal cost, but various reports have raised serious disadvantages due to their low ability to distinguish between lean and fat mass in an individual [6,7]. For these reasons, together with the great variability of body composition depending on gender, age group, ethnicity and socio-cultural habits [8]; the selection of the best anthropometric parameter able to predict morbidity and mortality from cardiometabolic diseases has been very controversial. 
Therefore, the main purpose of this study was to determine the predictive ability of various anthropometric parameters for the multiple risk factors aggregation in the adult population of the city of Maracaibo-Venezuela.

\section{Research Design and Methods}

\section{Subject Selection}

The Maracaibo City Metabolic Syndrome Prevalence Study (MMSPS) [9] was a cross-sectional research study undertaken in the city of Maracaibo-Venezuela, the second largest city in the country with 2.500 .000 inhabitants, with the purpose of identifying and analyzing MS and cardiovascular risk factors in our adult population. A total of 2,230 subjects were enrolled through a multi-stage random sampling, out of which 1,902 were selected after the exclusion of individuals without serum insulin levels determination, and those with a previous diagnosis of Type 2 Diabetes Mellitus (T2DM). The study was approved by the Bioethics Committee of the Endocrine and Metabolic Diseases Research Center - University of Zulia, and all participants signed a written consent before being interrogated and physically examined by a trained team.

\section{Clinical and Biochemical Evaluation}

Assessment of blood pressure was done using a calibrated mercury sphygmomanometer, with patients previously rested (during at least 15 minutes) in a sitting position with both feet touching the floor, the arm was positioned at heart level; a proper sized cuff was used for the procedure. The WHO classification for Obesity is based upon the BMI [10] [weight $\left./ \mathrm{height}^{2}\right]$ expressed in $\mathrm{kg} / \mathrm{m}^{2}$. Height was obtained using a calibrated rod, millimeters and centimeters, with the patient barefooted and his/her back facing the wall. Weight was recorded using a digital scale (Tanita, TBF-310 GS Body Composition Analyzer, Tokyo - Japan) with the patient using light clothing and no shoes. WC was assessed using calibrated measuring tapes in accordance the USA National Institutes of Health protocol [11]. WHtR was determined from waist circumference $(\mathrm{cm})$ divided by height $(\mathrm{cm})$. An antecubital blood sample was taken following an overnight fasting of 8-12 hours in order to measure the following: fasting blood glucose, total cholesterol, triacylglycerides (TAG) and High Density Lipoprotein-Cholesterol (HDL-C) with an enzymatic colorimetric technique and a computerized analyzer (Human, Magdeburg, Germany).

\section{Definitions}

Multiple Risk Factor Aggregation (MRFA) was defined as $\geq 2$ of the following: impaired fasting glucose ( $\geq 100 \mathrm{mg} / \mathrm{dL}$ or presence of diagnosis of T2DM), HBP (Systolic Blood Pressure $\geq 130 \mathrm{mmHg}$ and/or Diastolic Blood Pressure $\geq 85 \mathrm{mmHg}$; or history of antihypertensive usage), high TAG $(\geq 150 \mathrm{mg} / \mathrm{dL}$ or presence of treatment for this disorder), and low HDL-C $(<40 \mathrm{mg} / \mathrm{dL}$ in $\mathrm{males}$ and $<50 \mathrm{mg} / \mathrm{dL}$ in females or presence of treatment for this disorder).

\section{Statistical Analysis}

Normal distribution of continuous variables was evaluated by using Geary's test. For normally distributed variables, the results were expressed as arithmetic mean \pm SD (standard deviation). Variables without a normal distribution were logarithmically transformed, and normal distribution later corroborated. Differences between arithmetic mean were assessed using Student's $t$-test (when two groups were compared). Qualitative variables were expressed as absolute and relative frequencies. The Receiver Operating Characteristic (ROC) curves were constructed to expect presence of 2 or more metabolic components for MS, with the exception of WC. ROC Curves were plotted for each gender using R Project software for Statistical Computing. Cut-off points were selected using The Youden Index, the distance of the point closest to (0.1) on the ROC curve and the comparison of Area Under Curve (AUC) was calculated with DeLong's test. Two logistic regression models were calculated for MRFA (Dependent Variable), the first adjusted for: gender, age groups, ethnic groups, socioeconomic status and anthropometric parameters definitions. The second one adjusted for: gender, age groups, ethnic groups, socioeconomic status and amount of abnormal anthropometric parameter. Statistical analysis was done using the Statistical Package for the Social Sciences (SPSS) v19 for Windows (IBM Inc. Chicago, IL).

\section{Results}

\section{General characteristics of the Population}

A total of 1,902 subjects were studied (52.2\% females). The arithmetic mean of age was $38.7 \pm 15.0$ years, being the age group $20-29 \mathrm{yrs}$ the biggest one with $26.9 \%$ of the sample. The majority of the population was considered as mixed race (76.9\%), classified as Middle Class socioeconomic status (40.2\%), where 37\% displayed HBP, $24.1 \%$ showed dysglycemia, $26.1 \%$ hypertriacylglyceridemia, $56.5 \%$ has Low HDL-C levels, and $43.3 \%$ of the subjects had 2 or more risk factors (Table 1 ).

\section{Overall Anthropometric Evaluation}

Table 2 shows the results between subjects with or without MFRA according to gender, rendering significant differences between all variables. It's noteworthy to point out that all measurements were higher in those with positive MFRA than in those individuals whom had no risk aggregation, being grossly observed in WC with differences over $10 \mathrm{~cm}$ between such groups. 


\begin{tabular}{|c|c|c|c|c|c|c|}
\hline & \multicolumn{2}{|c|}{$\begin{array}{l}\text { Females } \\
(\mathrm{n}=992)\end{array}$} & \multicolumn{2}{|c|}{$\begin{array}{c}\text { Males } \\
(\mathbf{n}=910)\end{array}$} & \multicolumn{2}{|c|}{$\begin{array}{c}\text { Total } \\
(n=1902)\end{array}$} \\
\hline & $\mathbf{n}$ & $\%$ & $\mathbf{n}$ & $\%$ & $\mathbf{n}$ & $\%$ \\
\hline \multicolumn{7}{|l|}{ Age Groups (years) } \\
\hline $18-20$ & 87 & 8.8 & 70 & 7.7 & 157 & 8.3 \\
\hline $20-29$ & 218 & 22.0 & 294 & 32.3 & 512 & 26.9 \\
\hline $30-39$ & 176 & 17.7 & 178 & 19.6 & 354 & 18.6 \\
\hline $40-49$ & 230 & 23.2 & 164 & 18.0 & 394 & 20.7 \\
\hline $50-59$ & 170 & 17.1 & 136 & 14.9 & 306 & 16.1 \\
\hline$\geq 60$ & 111 & 11.2 & 68 & 7.5 & 179 & 9.4 \\
\hline \multicolumn{7}{|l|}{ Ethnic groups } \\
\hline Mixed & 757 & 76.3 & 706 & 77.6 & 1463 & 76.9 \\
\hline Hispanic White & 162 & 16.3 & 138 & 15.2 & 300 & 15.8 \\
\hline Afro-Venezuelan & 24 & 2.4 & 31 & 3.4 & 55 & 2.9 \\
\hline Amerindian & 39 & 3.9 & 34 & 3.7 & 73 & 3.8 \\
\hline Others & 10 & 1.0 & 1 & 0.1 & 11 & 0.6 \\
\hline \multicolumn{7}{|l|}{ Socioeconomic Status } \\
\hline Stratum I: High Class & 17 & 1.7 & 19 & 2.1 & 36 & 1.9 \\
\hline Stratum II: Upper middle Class & 172 & 17.3 & 175 & 19.2 & 347 & 18.2 \\
\hline Stratum III: Middle Class & 379 & 38.2 & 385 & 42.3 & 764 & 40.2 \\
\hline Stratum IV: Working Class & 373 & 37.6 & 301 & 33.1 & 674 & 35.4 \\
\hline Stratum V: Lower-Extreme Poverty & 51 & 5.1 & 30 & 3.3 & 81 & 4.3 \\
\hline High Blood Pressureg & 324 & 32.7 & 379 & 41.6 & 703 & 37.0 \\
\hline Impaired Fasting Glucose & 216 & 21.8 & 243 & 26.7 & 459 & 24.1 \\
\hline High Triacylglycerides $\psi$ & 206 & 20.8 & 290 & 31.9 & 496 & 26.1 \\
\hline Low HDL-C¥ & 624 & 62.9 & 451 & 49.6 & 1075 & 56.5 \\
\hline Elevated Waist Circumferences & 779 & 78.5 & 638 & 70.1 & 1417 & 74.5 \\
\hline Multiple Risk Factor Aggregation $\dagger$ & 395 & 39.8 & 429 & 47.1 & 824 & 43.3 \\
\hline TOTAL & 992 & 52.2 & 910 & 47.8 & 1902 & 100 \\
\hline
\end{tabular}

gystolic Blood Pressure $\geq 130 \mathrm{mmHg}$ and/or Diastolic Blood Pressure $\geq 85 \mathrm{mmHg}$ or history of antihypertensive usage $\ddagger \geq 100 \mathrm{mg} / \mathrm{dL}$ or presence of diagnosis of type 2 diabetes

$\psi \geq 150 \mathrm{mg} / \mathrm{dL}$ or presence of treatment for this disorder

$¥<40 \mathrm{mg} / \mathrm{dL}$ in males and $<50 \mathrm{mg} / \mathrm{dL}$ in females or presence of treatment for this disorder

$\$ \geq 90 \mathrm{~cm}$ in males and $\geq 80 \mathrm{~cm}$ in females

$\dagger$ Defined as $\geq 2$ of the following: High Blood Pressure, Impaired Fasting Glucose, High Triacylglycerides, Low HDL-C

Table 1: General characteristics of the general population according to gender. The Maracaibo City Metabolic Syndrome Prevalence Study, 2014

\begin{tabular}{|c|c|c|c|c|c|c|}
\hline & \multicolumn{2}{|c|}{$\begin{array}{c}\text { Females } \\
(\mathbf{n = 9 9 2 )}\end{array}$} & \multicolumn{2}{c|}{$\begin{array}{c}\text { Males } \\
(\mathbf{n = 9 1 0 )}\end{array}$} & \\
\hline & Without MRFA & With MRFA & & Without MRFA & With MRFA & \\
\hline & Mean \pm SD & Mean \pm SD & $p^{*}$ & Mean \pm SD & Mean \pm SD & $p^{*}$ \\
\hline Body Mass Index $\left.\mathbf{( K g} / \mathbf{m}^{2}\right)$ & $26.1 \pm 5.5$ & $30.3 \pm 6.5$ & $1.9 \times 10^{-24}$ & $26.7 \pm 5.3$ & $30.9 \pm 6.5$ & $6.1 \times 10^{-25}$ \\
\hline Waist-to-Height Ratio & $0.55 \pm 0.08$ & $0.62 \pm 0.09$ & $3.2 \times 10^{-34}$ & $0.54 \pm 0.08$ & $0.62 \pm 0.09$ & $2.0 \times 10^{-43}$ \\
\hline Waist Circumference $(\mathbf{c m})$ & $86.7 \pm 12.4$ & $96.8 \pm 13.4$ & $7.9 \times 10^{-32}$ & $92.2 \pm 13.1$ & $105.0 \pm 16.1$ & $1.3 \times 10^{-35}$ \\
\hline
\end{tabular}

$\left.{ }^{*}\right) t$-Student test (After logarithmic transformation)

MRFA=Multiple Risk Factor Aggregation; $\mathrm{SD}=$ Standard Deviation

Table 2: Anthropometric parameters by gender and presence of Multiple risk factor aggregation. The Maracaibo City Metabolic Syndrome Prevalence Study, 2014

\section{ROC curves for Anthropometric variables}

ROC curves were plotted for both genders to determine the BMI and WHtR cut-off values for MRFA in each gender (Figure 1). Based on the cut-off predicted value for WC, the results were $90.25 \mathrm{~cm}$ for women and $95.15 \mathrm{for}$ men. For WHtR, the cut-off points were similar for both genders with 0.56 for women and for men. The BMI cut-off point for females was $26.7 \mathrm{~kg} / \mathrm{m}^{2}$, and for males $27.5 \mathrm{~kg} / \mathrm{m}^{2}$. Table 3 shows the cut-off points for each anthropometric parameter with their respecting predicted values, as well as AUC comparisons according to gender. 

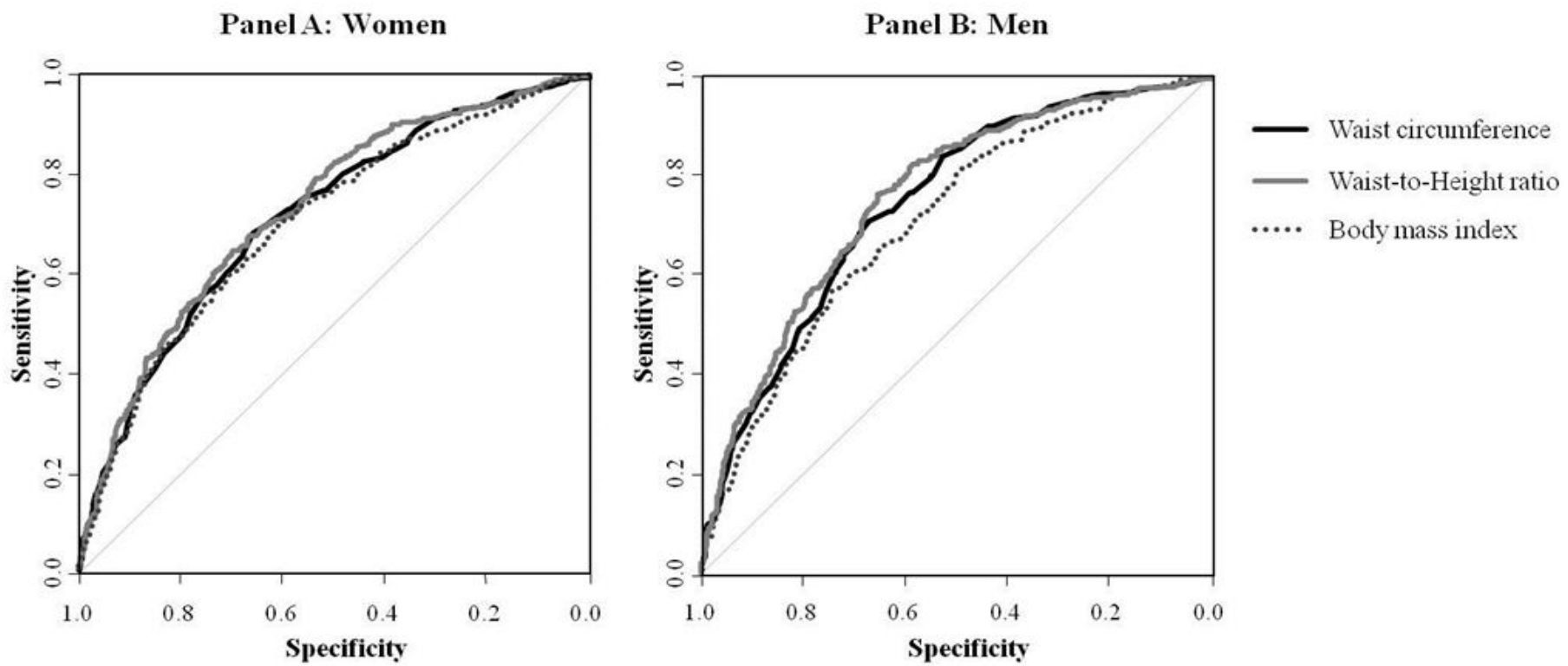

Figure 1: ROC curves constructed to determine Waist Circumference, Body Mass Index and Waist-to-Height ratio cut-off points for the detection of multiple risk factor aggregation. The Maracaibo City Metabolic Syndrome Prevalence Study, 2014

\begin{tabular}{|c|c|c|c|c|c|c|}
\hline & \multicolumn{3}{|c|}{ Anthropometric Parameters } & \multicolumn{3}{|c|}{ DeLong's test $(p)^{*}$} \\
\hline & $\begin{array}{l}\text { Waist Circumference } \\
\text { (A) }\end{array}$ & $\begin{array}{c}\text { Waist-to-Height } \\
\text { Ratio (B) }\end{array}$ & $\begin{array}{l}\text { Body Mass Index } \\
\text { (C) }\end{array}$ & A vs $B$ & A vs C & B vs C \\
\hline \multicolumn{7}{|l|}{ Females } \\
\hline Cutoffs point & $90.25 \mathrm{~cm}$ & 0.56 & $26.7 \mathrm{~kg} / \mathrm{m}^{2}$ & & & \\
\hline AUC (CI 95\%) & $0.716(0.684-0.748)$ & $0.725(0.693-0.757)$ & $0.700(0.667-0.733)$ & 0.073 & 0.100 & 0.009 \\
\hline Sensivity (\%) & 68.4 & 70.1 & 69.6 & & & \\
\hline Specificity (\%) & 65.8 & 62.5 & 61.5 & & & \\
\hline Youden Index & 0.34 & 0.33 & 0.31 & & & \\
\hline Distance to ROC & 0.465 & 0.479 & 0.492 & & & \\
\hline \multicolumn{7}{|l|}{ Males } \\
\hline Cutoffs point & $95.15 \mathrm{~cm}$ & 0.56 & $27.5 \mathrm{~kg} / \mathrm{m}^{2}$ & & & \\
\hline AUC (CI 95\%) & $0.746(0.715-0.778)$ & $0.760(0.729-0.791)$ & $0.712(0.679-0.745)$ & 0.601 & $1.99 \times 10^{-7}$ & $2.98 \times 10^{-6}$ \\
\hline Sensivity (\%) & 71.1 & 71.1 & 68.5 & & & \\
\hline Specificity (\%) & 67.4 & 68.6 & 60.7 & & & \\
\hline Youden Index & 0.39 & 0.40 & 0.29 & & & \\
\hline Distance to ROC & 0.435 & 0.426 & 0.503 & & & \\
\hline
\end{tabular}

${ }^{*}$ Differences between AUC

Table 3: Optimal cut-off values, area under curve, sensitivity, specificity, Youden Index and Distance to ROC of anthropomet-

ric parameters by gender. The Maracaibo City Metabolic Syndrome Prevalence Study, 2014

\section{Anthropometric variables and MFRA}

Anthropometric variables were categorized according to cut-off point and association was calculated, demonstrating that all 3 variables were associated with MFRA (Table 4). During the multivariable analysis, BMI and WHtR loss their association, while WC maintained it (Table 5). Moreover, an increasing pattern is observed when MFRA numbers of variables are grouped, that goes from $22.1 \%$ in the healthy group to $62.5 \%$ in the group with 3-factors MRFA (Figure 2). In a final multivariable analysis, a similar trend is shown with progressive increase in the value of the OR for MRFA as the number of anthropometric alterations are added, going from OR: 1.48 with 1 anthropometric variable to OR: 3.93 with 3-factors MRFA; $p<0.00001$, Figure 3.

\section{Discussion}

Several studies have reported that body composition assessed by BMI is a good predictor of cardiometabolic risk [12]. However, most research studies in this field have shown that the measurements body fat distribution is more important; therefore its accuracy makes central obesity markers the best predictors in morbidity and mortality for cardiovascular disease compared to BMI [13,14]. Based on different findings worldwide, an ongoing debate has developed concerning which of these anthropometric parameters provides clinicians with a better understanding of potential cardiometabolic risks in their patients. In this regard, our findings 


\begin{tabular}{|c|c|c|c|c|c|c|}
\hline & \multicolumn{2}{|c|}{ Without MRFA } & \multicolumn{2}{|c|}{ With MRFA } & \multirow[b]{2}{*}{$\chi^{2}(p)$} & \multirow[b]{2}{*}{$\mathbf{Z}$ Test $\mathbf{p}$} \\
\hline & $\mathbf{n}$ & $\%$ & $\mathbf{n}$ & $\%$ & & \\
\hline Body Mass Index & & & & & $163.66(<0.0001)$ & \\
\hline Normal & 651 & 60.4 & 254 & 30.8 & & $<0.05$ \\
\hline Elevated & 427 & 39.6 & 570 & 69.2 & & $<0.05$ \\
\hline Waist-to-Height Ratio $\psi$ & & & & & $233.79(0.00001)$ & \\
\hline Normal & 639 & 59.3 & 199 & 24.2 & & $<0.05$ \\
\hline Elevated & 439 & 40.7 & 625 & 75.8 & & $<0.05$ \\
\hline Waist Circumferenceg & & & & & $246.13(<0.00001)$ & \\
\hline Normal & 717 & 66.5 & 249 & 30.2 & & $<0.05$ \\
\hline Elevated & 361 & 33.5 & 575 & 69.8 & & $<0.05$ \\
\hline TOTAL & 1078 & 100.0 & 824 & 100.0 & & \\
\hline
\end{tabular}

MRFA=Multiple Risk Factor Aggregation

$\ddagger \geq 26.7 \mathrm{~kg} / \mathrm{m}^{2}$ in females and $\geq 27.5 \mathrm{~kg} / \mathrm{m}^{2}$ in males

$\psi \geq 0.56$ in both genders

9 $>90 \mathrm{~cm}$ in females and $>95 \mathrm{~cm}$ in males

Table 4: Association between anthropometric parameters classification and multiple risk factor aggregation. The Maracaibo City Metabolic Syndrome Prevalence Study, 2014

\begin{tabular}{|c|c|c|c|c|}
\hline & $\begin{array}{l}\text { Crude Odds Ratio } \\
\quad\left(\text { CI 95\% }{ }^{a}\right)\end{array}$ & $p^{b}$ & $\begin{array}{c}\text { Adjusted Odds } \\
\text { Ratio }^{\mathrm{c}} \\
(\text { CI 95\%) }\end{array}$ & $p^{b}$ \\
\hline \multicolumn{5}{|l|}{ Gender } \\
\hline Female & 1.00 & - & 1.00 & - \\
\hline Male & $1.35(1.12-1.62)$ & $<0.01$ & $1.73(1.40-2.13)$ & $<0.01$ \\
\hline \multicolumn{5}{|c|}{ Age Groups (years) } \\
\hline$<20$ & 1.00 & - & 1.00 & - \\
\hline $20-29$ & $1.13(0.72-1.76)$ & 0.60 & $0.73(0.46-1.17)$ & 0.19 \\
\hline $30-39$ & $2.39(1.52-3.74)$ & $<0.01$ & $1.30(0.81-2.09)$ & 0.29 \\
\hline $40-49$ & $5.58(3.59-8.68)$ & $<0.01$ & $2.96(1.85-4.75)$ & $<0.01$ \\
\hline $50-59$ & $7.04(4.46-11.12)$ & $<0.01$ & $3.68(2.26-5.99)$ & $<0.01$ \\
\hline$\geq 60$ & $10.47(6.29-17.48)$ & $<0.01$ & $5.59(3.23-9.68)$ & $<0.01$ \\
\hline \multicolumn{5}{|l|}{ Ethnic groups } \\
\hline Mixed & 1.00 & - & 1.00 & - \\
\hline Hispanic White & $1.16(0.90-1.49)$ & 0.24 & $1.04(0.78-1.39)$ & 0.78 \\
\hline Afro-Venezuelan & $1.38(0.80-2.36)$ & 0.25 & $1.46(0.80-2.67)$ & 0.22 \\
\hline Amerindian & $0.57(0.34-0.95)$ & 0.03 & $0.66(0.35-1.22)$ & 0.18 \\
\hline Others & $1.11(0.34-3.64)$ & 0.87 & $1.27(0.30-5.33)$ & 0.74 \\
\hline \multicolumn{5}{|l|}{ Body Mass Index } \\
\hline Normal & 1.00 & - & 1.00 & - \\
\hline Elevated & $3.42(2.82-4.14)$ & $<0.01$ & $1.33(0.99-1.78)$ & 0.06 \\
\hline \multicolumn{5}{|c|}{ Waist-to-Height Ratio $\psi$} \\
\hline Normal & 1.00 & - & 1.00 & - \\
\hline Elevated & $4.57(3.74-5.59)$ & $<0.01$ & $1.43(0.99-2.04)$ & 0.05 \\
\hline \multicolumn{5}{|c|}{ Waist Circumferenceg } \\
\hline Normal & 1.00 & - & 1.00 & - \\
\hline Elevated & $4.59(3.77-5.58)$ & $<0.01$ & $2.06(1.44-2.95)$ & $<0.01$ \\
\hline
\end{tabular}

a Confidence Interval (95\%), b Significance Level

c Ajusted for: Gender, Age groups, Ethnic Groups, Socioeconomic Status and anthropometric parameters definitions

$\ddagger \geq 26.7 \mathrm{~kg} / \mathrm{m}^{2}$ in females and $\geq 27.5 \mathrm{~kg} / \mathrm{m}^{2}$ in males

$\psi \geq 0.56$ in both genders

g $>90 \mathrm{~cm}$ in females and $>95 \mathrm{~cm}$ in males

Table 5: Multivariable analysis of anthropometric parameters classification for multiple risk factor aggregation. The Maracaibo City Metabolic Syndrome Prevalence Study, 2014 


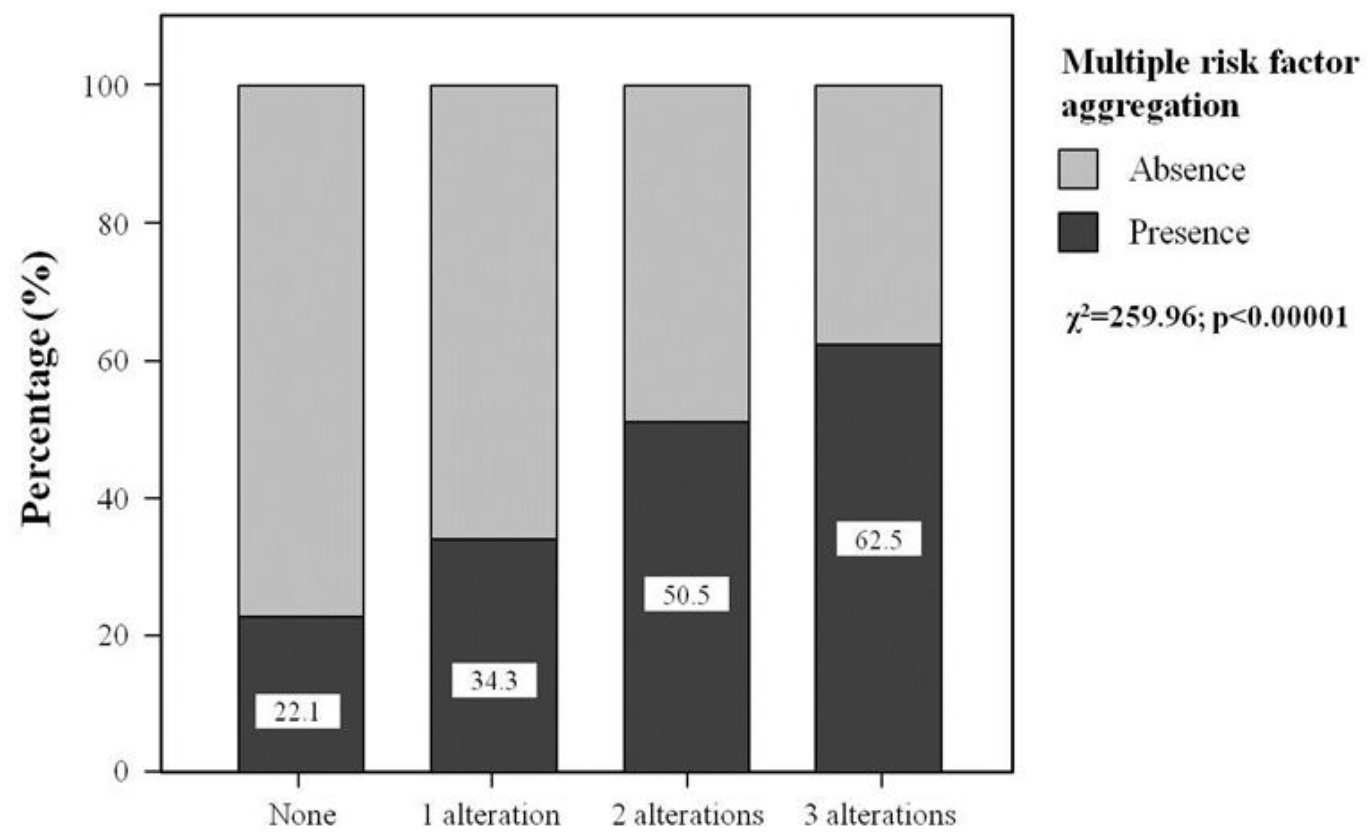

Number of altered Anthropometric variables

Figure 2: Distribution of the subjects with Multiple Risk Factor Aggregation according to the number of alterations present. The Maracaibo City Metabolic Syndrome Prevalence Study, 2014

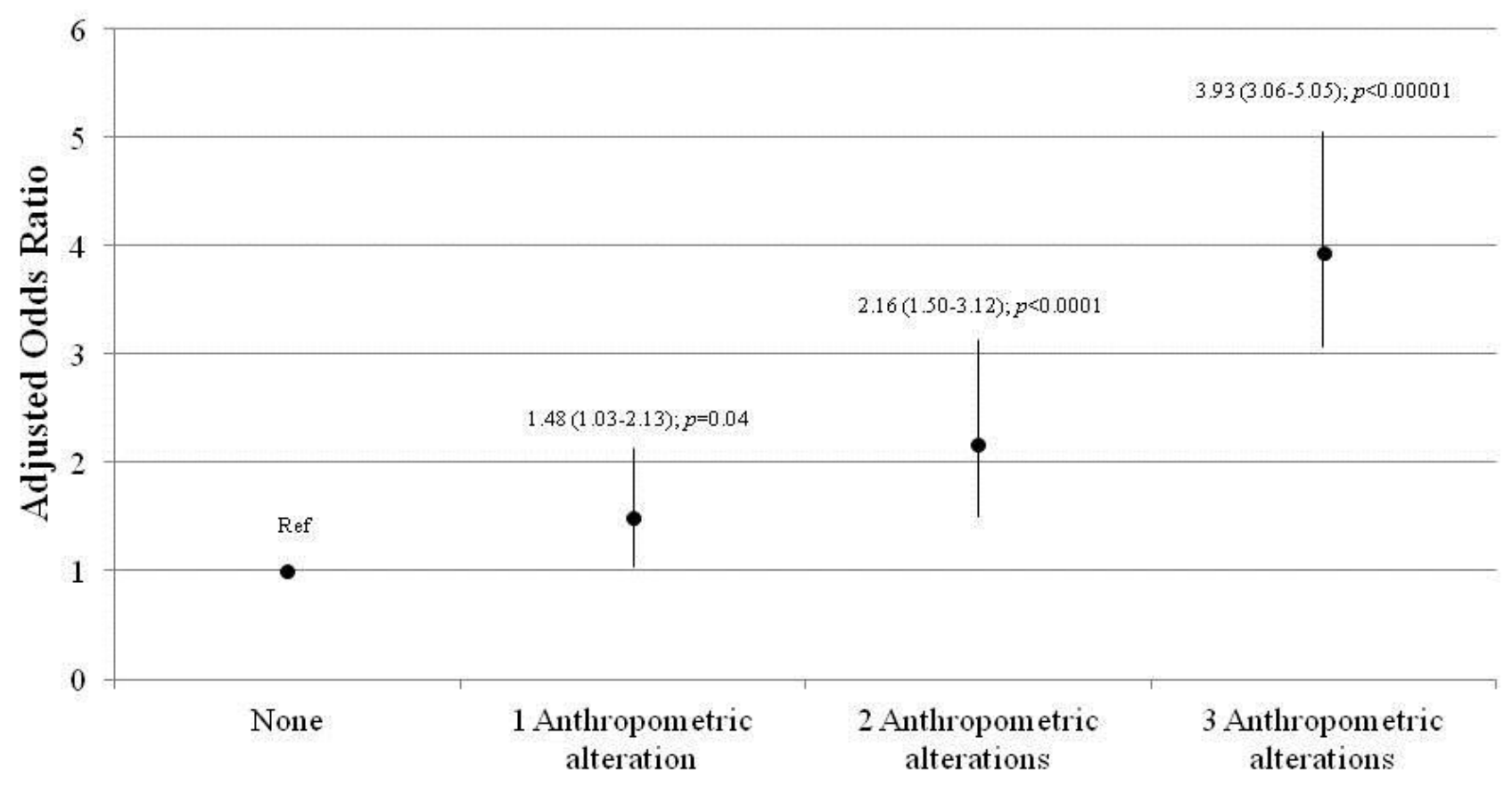

Adjusted for: Gender, Age groups, Ethnic Groups, Socioeconomic Status and number of altered anthropometric variables.

Figure 3: Odds Ratios adjusted according to number of altered anthropometric parameters and MRFA. The Maracaibo City Metabolic Syndrome Prevalence Study, 2014

show that various anthropometric parameters exhibit varying degrees of predictive capacity for MRFA in both men and women (at or above 0.70 AUC). This confirms that anthropometric alterations are linked to obesity, regardless of the index or measure that is used, are closely related to dyslipidemia, hypertension, dysglycemia, among other metabolic disorders [15-17]. Such variables a series of risk factors that predispose from childhood to major chronic diseases with a significance epidemiological importance worldwide $[18,19]$. 
During the assessment of anthropometric parameters individually by gender, it shows that WHtR in women is more predictable than BMI, and WC was better for predicting MRFA. These findings differ from those reported by Mora-Garcia et al. [20] in the female population of the city of Cartagena (Colombia), publishing that WHtR was the only parameter associated with MS (ergo MRAF). However, several meta-analysis have shown that WHtR is a diagnostic tool and important cardiometabolic risk predictor parameter not only in adults but also in individuals, including young adults and teenagers [21-23]. Moreover, in men both WC and WHtR show a higher similar predictive capacity over BMI, results that differ from those shown by Liu et al. [24] in adults from Liaoning Province in China, reporting that the 3 variables show no difference in their behavior. Nevertheless, Bener et al. [25] published their evaluation of anthropometric variables and MS prediction in the Qatari population, suggesting that WC was the measurement with higher predictive power for MS, followed by the waist-hip-ration and WHtR.

Once cut-off points were obtained applying ROC curve analysis, the association between anthropometric parameters showed a similar development evidenced by the curves plots, with an increased risk of MRFA for those exhibiting abdominal obesity and high WHtR. This demonstrates the importance of body fat distribution and its influence on the appearance of several metabolic disorders associated with the accumulation of dysfunctional adipocytes capable of synthesizing a large number of proinflammatory molecules, a condition known as "adiposopathy" and which forms the basis for different molecular metabolic diseases such as dyslipidemia, T2DM and MS [26,27].

It is important to highlight the relationship shown in this study between abdominal circumference and MRFA, because it differs from previous reports where the predictive capacity of abdominal obesity for MS was shown, without considering the autocorrelation generated by not exclude it from assessment of the outcome $[20,25,28]$. Likewise, cut-off points for each parameter show the importance of their adjustment to the characteristics of each region; in the case of WC the values have been previously detailed by our research team [29]. For WHtR the cut-off points are slightly higher than those shown in most reports worldwide $[30,31]$, whereas BMI cutoffs are lower than those used for the diagnosis of obesity (WHO), which has already been suggested by Nieto et al. [32] in our population. Therefore, beyond recommending a specific parameter in detecting risk factors such as Peruvians [33], our main finding is that there is a high association between MRFA and the presence of a higher number of altered anthropometric parameters, results that were evidence in both univariate and multivariate context. This demonstrates the importance of determining the highest amount of anthropometric measurements in clinical practice, as a key strategy to improve diagnostic capacity of individual indexes.

Among our limitations is the cross-sectional nature of the study, making it impossible to establish a causal relation for each anthropometric parameter. Nevertheless, few locally studies have evaluated the role of anthropometric measurements and their impact on the determination of the main cardiometabolic abnormalities that affect Latin America and the Caribbean [34]. Furthermore, this study is the first analysis of a series of reports where anthropometric indexes isolated with adiposity indexes are compared, combining anthropometric and metabolic variables.

We can conclude that WC provides greater predictive ability of MRFA compared to other parameters. Further studies are needed to properly understand the influence of WC in the clustering of metabolic variables and how ethnicity might influence such predictive power.

\section{Acknowledgment}

This work was supported by Research Grant no. CC-0437-10-21-09-10 from Consejo de Desarrollo Científico, Humanístico y Tecnológico (CONDES), University of Zulia, and Research Grant no. FZ-0058-2007 from Fundacite-Zulia.

\section{References}

1. WHO Expert Committee (1995) Physical status: The use and interpretation of anthropometry, Geneva.

2. Keys A, Fidanza F, Karvonen MJ, Kimura N, Taylor HL (1972) Indices of relative weight and obesity. J Chronic Dis 25: 329-43.

3. WHO (2008) Waist circumference and waist-hip ratio: report of a WHO expert consultation, Geneva.

4. Hsieh SD, Yoshinaga H (1995) Abdominal fat distribution and coronary heart disease risk factors in men-waist/height ratio as a simple and useful predictor. Int J Obes Relat Metab Disord 19: 585-9.

5. Millar SR, Perry IJ, Phillips CM (2013) Surrogate Measures of Adiposity and Cardiometabolic Risk - Why the Uncertainty? A Review of Recent Meta-Analytic Studies. J Diabetes Metab S11: 004.

6. Michels KB, Greenland S, Rosner BA (1998) Does body mass index adequately capture the relation of body composition and body size to health outcomes? Am J Epidemiol 147: 167-72.

7. Shah NR, Braverman ER (2012) Measuring Adiposity in Patients: The Utility of Body Mass Index (BMI), Percent Body Fat, and Leptin. PLoS ONE 7: e33308.

8. Ellis KJ (2000) Human Body Composition: In Vivo Methods. Physiol Rev 80: 649-80.

9. Bermúdez V, Marcano RP, Cano C, Arráiz N, Amell A, et al. (2010) The Maracaibo City Metabolic Syndrome Prevalence Study: Design and Scope. Am J Ther 17: $288-94$.

10. WHO (2003) The World Health Report 2003. 
11. Health Statistics (1988) National Health and Nutrition Examination Survey III Body Measurements (Anthropometry) Rockville, MD, USA.

12. Romero-Corral A, Somers VK, Sierra-Johnson J, Thomas RJ, Collazo-Clavell ML, et al. (2008) Accuracy of body mass index in diagnosing obesity in the adult general population. Int J Obes 32: 959-66.

13. Janssen I, Katzmarzyk PT, Ross R (2004) Waist circumference and not body mass index explains obesity-related health risk. Am J Clin Nutr 79: $379-84$.

14. Lee CM, Huxley RR, Wildman RP, Woodward M (2008) Indices of abdominal obesity are better discriminators of cardiovascular risk factors than BMI: a metaanalysis. J Clin Epidemiol 61: 646-53.

15. von Eyben FE, Mouritsen E, Holm J, Montvilas P, Dimcevski G, et al. (2003) Intra-abdominal obesity and metabolic risk factors: a study of young adults. Int J Obes Relat Metab Disord 27: 941-9.

16. Kotchen TA (2010) Obesity-related hypertension: epidemiology, pathophysiology, and clinical management. Am J Hypertens 23: 1170-8.

17. Nakao YM, Kawakami K (2014) Abdominal Obesity: Why it Matters. J Obes Weight Loss Ther 4: e111.

18. Caprio S (2012) Development of type 2 diabetes mellitus in the obese adolescent: a growing challenge. Endocr Pract 18: 791-5.

19. Espinel PT, King L, Hector D (2012) Obesity and chronic disease prevention among older adults (55-74 years): An evidence overview and framework to inform policy and practice, Sydney; Physical Activity Nutrition \& Obesity Research Group, Australia.

20. Mora-García GJ, Gómez-Camargo D, Mazenett E, Alario Á, Fortich Á, et al. (2014) Anthropometric parameters' cut-off points and predictive value for metabolic syndrome in women from Cartagena, Colombia. Salud Publica Mex 56: 146-53.

21. Ashwell M, Gunn P, Gibson S (2012) Waist-to-height ratio is a better screening tool than waist circumference and BMI for adult cardiometabolic risk factors: systematic review and meta-analysis. Obes Rev 13:275-86.

22. Savva SC, Lamnisos D, Kafatos AG (2013) Predicting cardiometabolic risk: waist-to-height ratio or BMI. A meta-analysis. Diabetes Metab Syndr Obes 6: 403-19.

23. Pereira PF, Serrano HMS, Queiroz Carvalho G, Lamounier JA, Peluzio MCG, et al. (2011) Waist and waist-to-height ratio: useful to identify the metabolic risk of female adolescents? Rev Paul Pediatr 29: 372-7.

24. Liu Y, Tong G, Tong W, Lu L, Qin X (2011) Can body mass index, waist circumference, waist-hip ratio and waist-height ratio predict the presence of multiple metabolic risk factors in Chinese subjects? BMC Public Health 11: 35.

25. Bener A, Yousafzai MT, Darwish S, Al-Hamaq AO, Nasralla EA, et al. (2013) Obesity index that better predict metabolic syndrome: body mass index, waist circumference, waist hip ratio, or waist height ratio. J Obes 10.1155/2013/269038.

26. Bays H, Abate N, Chandalia M (2005) Adiposopathy: sick fat causes high blood sugar, high blood pressure and dyslipidemia. Future Cardiol 1: 39-59.

27. Bermúdez V, Rojas J, Aguirre M, et al. (2011). The Sick Adipocyte Theory: The Forces of Clustering at Glance, In: Role of the Adipocyte in Development of Type 2 Diabetes, InTech.

28. Gharipour M, Sarrafzadegan N, Sadeghi M, Andalib E, Talaie M, et al. (2013) Predictors of metabolic syndrome in the Iranian population: waist circumference, body mass index, or waist to hip ratio? Cholesterol 10.1155/2013/198384.

29. Bermúdez V, Rojas J, Salazar J, Añez R, Chávez-Castillo M, et al. (2014) Optimal Waist Circumference Cut-Off Point for Multiple Risk Factor Aggregation: Results from the Maracaibo City Metabolic Syndrome Prevalence Study. Epidemiol Res Int 10.1155/2014/718571.

30. Schneider HJ, Friedrich N, Klotsche J, Pieper L, Nauck M, et al. (2010) The predictive value of different measures of obesity for incident cardiovascular events and mortality. J Clin Endocrinol Metab 95: 1777-85.

31. Jayawardana R, Ranasinghe P, Sheriff MH, Matthews DR, Katulanda P (2013) Waist to height ratio: a better anthropometric marker of diabetes and cardiometabolic risks in South Asian adults. Diabetes Res Clin Pract 99: 292-9.

32. Nieto-Martínez R, Pérez Y, Suárez MA, Ugel E (2013) A BMI of 27.5 can improve the detection of obesity in a Venezuelan population. Diabetes 62: A750.

33. Knowles KM, Paiva LL, Sanchez SE, Revilla L, Lopez T, et al. (2011) Waist Circumference, Body Mass Index, and Other Measures of Adiposity in Predicting Cardiovascular Disease Risk Factors among Peruvian Adults. Int J Hypertens 10.4061/2011/931402.

34. Miranda JJ, Herrera VM, Chirinos JA, Gómez LF, Perel P, et al. (2013) Major cardiovascular risk factors in Latin America: a comparison with the United States. The Latin American Consortium of Studies in Obesity (LASO). PLoS One 8: e54056.

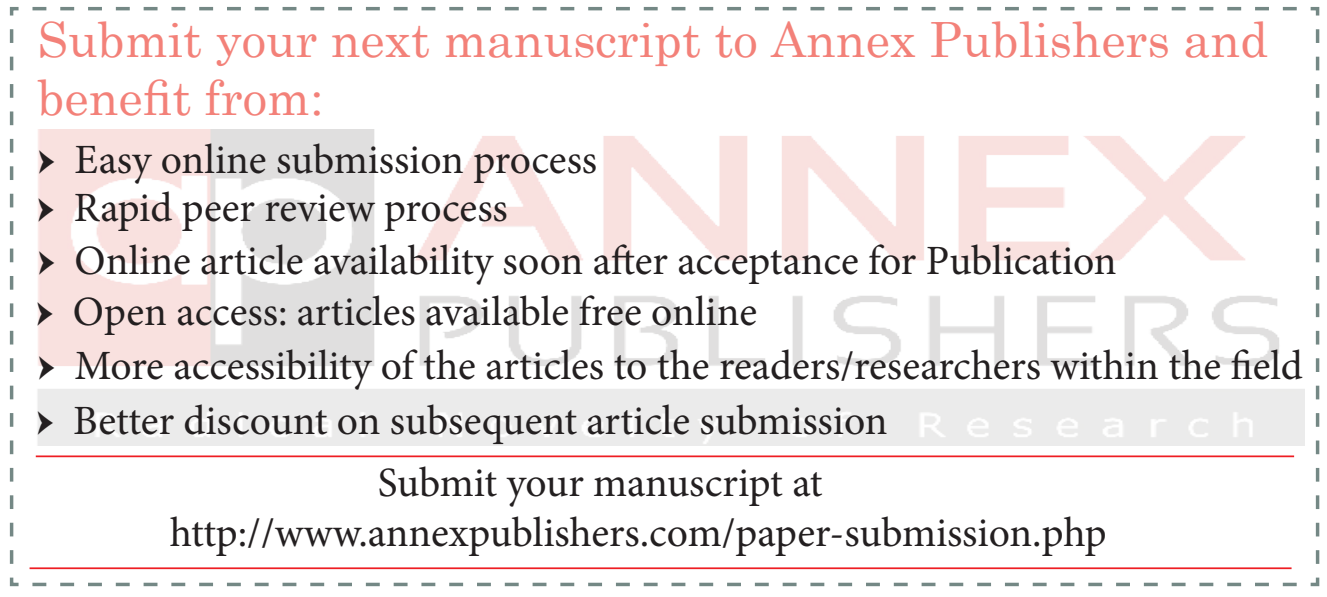

